PSICOLOGIA,SAÚDE \& DOENÇAS, 2017, 18(2), 602-613

ISSN - 2182-8407

Sociedade Portuguesa de Psicologia da Saúde - SPPS - www.sp-ps.com

DOI: http://dx.doi.org/10.15309/17psd180226

\title{
FAMILY OF PEOPLE WITH SPINA BIFIDA: GOALS AND STRATEGIES
}

\author{
Viviam Rafaela Barbosa Pinheiro Freire ${ }^{1,3-5}$, Simone Souza da Costa Silva ${ }^{1,4}$, Fernando Augusto Ramos \\ Pontes $^{1,5}$, Maély Ferreira Holanda Ramos ${ }^{1,6}$, \& Fabiana Faleiros Santana Castro, \\ ${ }^{1}$ Federal University of Pará. Belém - Pará - Brazil. ${ }^{2}$ University of São Paulo. São Paulo - Brasil. \\ ${ }^{3}$ e-mail: viviamrafaela@gmail.com. ${ }^{4}$ e-mail: symonufpa@ gmail.com. ${ }^{5}$ e-mail.Farp1304@ gmail.com. ${ }^{6}$ e-mail: \\ maelyramos@hotmail.com. 7 e-mail: fabifaleiros@eerp.usp.br
}

\begin{abstract}
We aim to describe the goals and strategies of action that parents have established for their child and young adults with spina bifida. Participants were 17 families who answered an online questionnaire. The instrument included topics about sociodemographic characteristics and the following questions: "How do you imagine your son's or daughter's life in the future?" and "What do you think he or she needs to develop these characteristics?". Data of socialization goals were analyzed according to the categories: Self-improvement, Self-control, Emotionality, Social Expectations and Good Behavior. Data of strategies of action were classified in the categories: Self-centered, Context-centered and Person-centered. Main results showed that the most valued socialization goal is selfimprovement which is similar to other German families, suggesting that the disability condition does not interfere in the culturally shared beliefs. In order to achieve their goals, parents use, primarily, the self-centered strategy, which represents parents want to serve as a model to their son or daughter with spina bifida. In addition, it was possible to identify that those mothers and fathers also tend to combine different strategies in order not only to maximize the developmental gains, but also to obtain social support in the parental role. In fact, parents of people with spina bifina should be supported in their needs since disability condition seems to be the major factor in the establishment of goals and strategies.
\end{abstract}

Keywords: family, socialization goals, spina bifida, strategies of action.

\section{FAMÍLIAS COM ESPINHA BÍFIDA: OBJETIVOS E ESTRATÉGIAS}

RESUMO: O objetivo deste trabalho é descrever as metas e estratégias de ação que pais e mães estabeleceram para sua criança ou adolescente com espinha bífida. Participaram 17 famílias que responderam a um questionário online. $\mathrm{O}$ instrumento incluiu tópicos sobre características sociodemográficas e as seguintes perguntas: "Como você imagina a vida de do seu filho ou filha no futuro?" e "O que você acha que é necessário para ele ou ela desenvolver estas características?" Dados de metas de socialização foram analisados de acordo com as categorias: Autoaperfeiçoamento, Autocontrole, Emotividade, Expectativas Sociais e Bom Comportamento. Os dados de estratégias de ação foram classificadas nas categorias: Centrada em si, Centrada na pessoa e Centrada no contexto. Os Principais resultados mostraram que a meta de socialização mais valorizada é autoaperfeiçoamento, o que é semelhante a outras famílias alemãs, sugerindo que a condição de deficiência não interfere nas crenças culturalmente compartilhadas. A fim de atingir seus objetivos, os pais usam, principalmente, a

Augusto Correa Street, 01, Belém - Pará - Brazil. Telf.:: (91) 980878716. e-mail: viviamrafaela@ hotmail.com 
estratégia centrada em si, o que representa que os genitores querem servir como um modelo para seu filho ou filha com espinha bífida. Além disso, foi possível identificar que as mães e pais também tendem a combinar estratégias diferentes, não apenas para maximizar os ganhos de desenvolvimento, mas também para obter apoio social no exercício do papel parental. Assim, os pais e mães de pessoas com espinha bífida devem ser apoiados nas suas necessidades, uma vez que a condição de deficiência parece ser o principal fator no estabelecimento de metas e estratégias.

Palavras-Chave: espinha bífida, estratégia de ação, família, metas de socialização

Recebido em 06 de Novembro de 2015/ Aceite em 04 de Abril de 2017

Socialization goals are related to parental cognitions, representing perspectives on the trajectories of the new generations. For Miller and Harwood (2001), these ideas include culturally shared values and beliefs that influence the use of care practices, in other words, parental behaviors considered culturally appropriated (Keller, 2007). Thus, socialization goals are concepts that drive the use of parenting strategies related to developmental targets.

Within this framework, parents establish goals for their children following two main tendencies: the independent and interdependent models. Families of highly educated adults with few children who live in urban environments of industrialized Western societies represent the independent model. For these groups, the main socialization goals include the expectation that the sons and daughters to be able to be alone and show self-confidence and autonomy in decision-making. On the other hand, families who live in rural environment characterized by reduced formal education, early parenting and high fertility represent the interdependent model. For these groups, the main socialization goals include having a life in harmony with family members and community (Keller, 2007).

Kagitcibasi (2007), in turn, presented the autonomous-relational model. It combines the features of goals related to both autonomy and interpersonal relationships (Kagitcibasi, 2007; Keller et al., 2006). This trend characterizes societies in transition between collectivism and individualism, such as those living in developing countries like Brazil.

Many studies identified these three models and their characteristics. Keller et al. (2005) investigated 129 family groups who lived in different places: rural area in Cameroon, urban area in Costa Rica and urban area in Germany. Through interviews and video records of play situations between mother and children, it was found that German mothers tend to promote independence, including more face-to-face interactions and object stimulation. Cameroonian mothers showed more body contact and body stimulation, characteristics related to interdependence. Costa Rican mothers showed evidence of both orientations, which suggests a tendency to self-relational model.

Further confirmation was obtained with the research on socialization goals of Turkish mothers who lived in Germany and German mothers who lived in their homeland. In this case, Durgel, Leyendecker, Yagmurlu and Harwood (2009) pointed out that the Turkish mothers were more likely to expect their sons and daughters were well-educated and had close relationship with the family. In addition, the Turkish mothers who were more integrated into German culture valued more individualistic goals, such as selfcontrol, than the Turkish mothers who were more distant from German culture, although both value mutual support within the family (Durgel, Leyendecker, Yagmurlu \& Harwood, 2009).

There is growing recognition that Germany is an example of independent model context. This indicates that, culturally, the most valued socialization goals by German parents are those related to the autonomy of sons and daughters. As noted by Biasoli-Alves (1997), this hope that children achieve 


\section{FAMILY OF PEOPLE WITH SPINA BIFIDA}

independence, being a competitive adult, has been a parental strategy to the demands of the globalized world.

Certainly, mothers and fathers make use of strategies for achieving their goals. According to Leyendecker, Lamb, Harwood and Schölmerich (2002) social and personal values of parents are related to strategies they use to reach desired behaviors for the sons and daughters. Thus, the way parents educate children reflects on various development indicators, such as self-esteem, depression, anxiety, academic performance, interpersonal competence and aggressive behavior (Kobarg, Sachetti \& Vieira, 2006; Teixeira, Oliveira, \& Wottrich, 2006).

Although the strategies aim the achievement of certain socialization goals, parental actions and their effects may change depending on different factors. As noted by Bandeira and Seidl-de-Moura (2012), behavior of parents may change throughout the life cycle, including those that occur in the different child age. Moreover, determination of parental strategies on the behavior of sons and daughters depends on the child's health condition (Ievers, 1998).

Particularly in this case, parental goals and strategies vary not only according to the context, but also the characteristics of their sons and daughters. This aspect is evident when considering parental goals of people with disabilities. Nuernberg (2008) argues that the lack of expectation and beliefs about the potential of a person with atypical development is common, resulting in restrictions of the conditions that favor overcoming the difficulties. Other research indicates negative expectations about the future in families of a disabled person (Couto et al., 2007; Sousa, Ribeiro \& Melo, 2009). Consequently, parents may have difficulty to stimulate children to be independent, partly due to imposing tight limits and overprotective attitudes (Prado, 2005).

A chronic childhood condition that can change the balance of the family and interfere in the parental actions is spina bifida. Considered the most common disability of neural tube, with an incidence of one in 1,000 births in the United States and 1.5 to 3 per 1000 births in Europe (Gaíva, Correa \& Santo, 2011), spina bifida is characterized by a congenital malformation of the central nervous system due to incomplete closure of the neural tube. The most serious and frequent form is Myelomeningocele, described as leakage of spinal cord or nerve roots due to the total or partial absence of the posterior arch of some vertebrae (Gaiva, Neves \& Smith, 2009). It is still unknown exactly the reasons why spina bifida occurs, but the folic acid deficiency is considered the main risk factor, since such acid is essential for cell division during fetal development (Aguiar et al., 2003).

Spina bifida can occur in any region of the spinal cord, such as thoracic, lumbar and sacral level, and the location of the defect is inversely proportional to the functional development and to the motor performance of the lower members (Bartonek, 2010). In addition it is common the presence of complications, like hydrocephalus, neurogenic bladder, bowel dysfunction, orthopedic problems, paralysis of the lower limbs as soon as contextual and social restrictions (Gaíva, Correa \& Santo, 2011). As noted by Barf et al. (2007) social participation of young people with spina bifida resident in Germany is limited due to accessibility barriers, emotional barriers, financial and motor constraints. Despite these difficulties, most young people with spina bifida who live in Germany affirmed to be satisfied with life, partly due to contact with family and friends (Barf et al., 2007).

Spina bifida's treatment requires surgery as early as possible to close the opening of the neural tube. Most modern interventions are performed during intrauterine life in order to preserve the neural function, reduce risk of infection and promote the development of the baby. Often additional surgeries and great medical care are needed throughout life (Assis \& Martinez, 2011; Gaíva, Correa \& Santo, 2011).

Given the complexity of spina bifida and other conditions of disability, parents have developed different perceptions about atypical development. Sousa et al. (2009) investigated in Brazil the socialization goals of 11 mothers and one father who had a Down syndrome child. As a result, parents 
expect the disabled child to become independent and to develop motor skills that enable locomotion and playing sports. So, they valued goals related to independent model.

More specifically, other research explored parental experience only about rehabilitation goals for the sons or daughters with disabilities. The authors (Wiart et al., 2010) conducted a qualitative study with 11 focus groups and two individual interviews with mothers and fathers of children with cerebral palsy. The data showed that the most important parents' goals are related to the following aspects: a) Motor and functional improvements; b) good health and physical condition; c) happiness, fulfilling life and social acceptance.

Sari and Marcon (2008) conducted a study about rehabilitation goals with mothers of children with cerebral palsy. Through semi-structured interviews with 28 women whose children were enrolled in a rehabilitation school, the authors identified that the main expectation is that his son or daughter can walk without support and has motor independence. On the other hand, Gondim and Carvalho (2012) identified that mothers fear about the future of their child with cerebral palsy, and these women reported partial or no cooperation from others, what leads to negative physical and psychological consequences for their health.

Besides socialization goals, parents adopt strategies of action to achieve their developmental objectives for their sons and daughters. Based on the category system of Bandeira, Seidl-de-Moura and Vieira (2009), Freitas and Magalhães (2013) investigated mothers of deaf children who lived in the Amazon and found that the self centered strategies were prevalent. It indicated that mothers believed their actions were key to achieving developmental gains for their children. In terms of socialization goals, social expectations were highligted, including the expectation that kids become a good professional, finish the studies and be successful in life. In addition, the authors noted that those women appreciated good behavior goals, such as when the sons and daughters become good people and have their own families. The authors concluded that mothers of deaf children had similar goals and strategies of actions as mothers of hearing children who live in the Amazon region.

Another study showed that Brazilian parents of children with Down syndrome had similar expectations of life to parents of people without disabilities, despite the limitations (Portes, 2013). Besides that, the most valuable strategy of action was self-centered, followed by the categories context-centered and childcentered. thus, the author argues that while parents believe they are primarily responsible for the achievement of expected behaviors, they also valued context-centered strategies, which is associated with the importance of social support network. On the other hand, when assigning less importance to childcentered strategies, mothers and fathers do not seem to believe that the son or daughter with Down syndrome can play an active role in promoting his or her own development, therefore, they need help from parents and from social network.

Indeed, family members of people with atypical development need effective support networks, particularly with regard to educational practices (Minetto, Crepaldi, Bigras \& Moreira, 2012). Specifically in the case of spina bifida the challenge is great, partly due to the delay in the acquisition of skills. For example, Daves et al. (2006) demonstrated that young people with myelomeningocele have a delay from two to five years on the achievements of autonomy when compared to people of the same age. In addition, parents of pre-teen with spina bifida claim that the sons and daughters have difficulty with their self-care, motivational factors and memory (Holmbeck \& Devine, 2010).

According to the aspects highlighted the presence of children or young adults with developmental alterations requires the adoption of strategies that allow achieving the goals established according to personal and social values (Leyendecker, Lamb, Harwood \& Schölmerich, 2002). Although the large number of periodicals which were dedicated to goals and parenting strategies, little is known about the beliefs of parents facing people with disabilities, including how investing in their developmental path. 


\section{FAMILY OF PEOPLE WITH SPINA BIFIDA}

In line with it, we aim to describe the socialization goals and strategies that mothers and fathers have established for their child and young adults with spina bifida. These aspects will allow knowing the meanings of parental beliefs and their influence on care practices, particularly, in relation to people with disabilities. More specifically, ideas and parental beliefs about development tend to be shared by groups of people of the same cultural context (Keller, 2007; Super \& Harkness, 1996). Although families share a specific belief, we intend to know the parental goals and strategies concerning the care of a disabled person, particularly in spine bifida condition.

\section{METHOD}

\section{Participants}

Seventeen families who lived in Germany and had a son or daughter with spina bifida participated in this study. Table 1 shows some characteristics of people with spina bifida and their families, including the age of the parents and sons and daughters, these genres, level of spina bifida, hydrocephalus presence and family income.

Table 1.

Demographic characteristics of participants

\begin{tabular}{|c|c|c|c|c|c|c|c|c|c|c|c|}
\hline $\begin{array}{l}\text { Parents' } \\
\text { age } \\
\text { (years) }\end{array}$ & $f$ & $\begin{array}{c}\text { Son's or } \\
\text { daughter's age } \\
\text { (years) }\end{array}$ & $f$ & $\begin{array}{l}\text { Son's or } \\
\text { daughter's } \\
\text { gender }\end{array}$ & $f$ & $\begin{array}{l}\text { Level of } \\
\text { Spina } \\
\text { bífida }\end{array}$ & $f$ & hydrocephalus & $f$ & $\begin{array}{c}\text { Family } \\
\text { Income (Euro) }\end{array}$ & $f$ \\
\hline $25-30$ & 3 & $0-5$ & 8 & Male & 4 & Thoracic & 4 & Yes & 16 & $500-2000$ & 4 \\
\hline $31-35$ & 6 & $6-10$ & 2 & Female & 13 & Lumbar & 9 & No & 1 & $2001-3500$ & 9 \\
\hline $36-40$ & 3 & $11-15$ & 3 & & & Sacral & 2 & & & $3501-5000$ & 2 \\
\hline $41-45$ & 4 & 16 or older & 4 & & & $\begin{array}{c}\text { Not } \\
\text { Reported }\end{array}$ & 2 & & & $\begin{array}{l}\text { More than } \\
5000\end{array}$ & 1 \\
\hline $\begin{array}{l}46 \text { or } \\
\text { older }\end{array}$ & 1 & & & & & & & & & Not Reported & 1 \\
\hline
\end{tabular}

The parents age ranged from 25-54 years, mean of $36.84(\mathrm{SD}=7.27)$. The age of the sons or daughters ranged from zero to 20 years, mean of 7.87 ( $\mathrm{SD}=7.09$ ). Most were girls (13), whose spina bifida was prevalent in the level of low back (9). There was presence of hydrocephalus in most cases (16). Finally, most families were in range of family income from 2001 to 3500 Euros (9).

\section{Material}

This study was conducted through online questionnaire software (Survey Monkey) in 2012. This source has tools of collection and analysis of virtual data and is available on the website http://www.surveymonkey.com. Families participated virtually through an instrument consisting of questions about sociodemographic characteristics (age, gender, educational level, family income, level of spina bifida and the presence of hydrocephalus) and the following questions: "How do you imagine your son's or daughter's life in the future?" and "What do you think he or she needs to develop these 
characteristics?". In this online questionnaire, It was also attached a consent form to participate in scientific research, which presented the research objectives and requested permission to use the collected data. For the preparation and translation of the questionnaire, we counted on partnership of German researchers from the University of Dortmund (Germany).

\section{Procedures}

This research was initially approved by the faculty committee of School of Rehabilitation Sciences Universidadade of Dortmund and the board of directors of German Association of Spina Bifida and Hydrocephalus. Participants could access the survey in the following websites: School of Rehabilitation Sciences, University of Dortmund (www.fk-reha.tu-dortmund.de); German Association for Spina Bifida and Hydrocephalus (http://www.asbh.de); and the Sternchenforum, an online help service for families and people with Spina Bifida and Hydrocephalus, which operates in partnership with the association (www.sternchenforum.de). Completing the survey was voluntary and participants' anonymity was maintained by the use of codes like P1, P2, P3 and etc.

Data analysis was conducted using NVivo qualitative analysis software which allowed analyzing the virtual questionnaire based on Bardin's content analysis (Bardin, 1977), using predetermined categories according to the literature. In addition, it was possible to elaborate a word cloud (visual representation of the words participants have said more frequently) and a conceptual map (where the categories of goals and strategies were associated).

The question "How do you imagine your son's or daughter's life in the future?" allowed accessing data of socialization goals according to the classification proposed by Miller and Harwood (2001). Categories are: Self-improvement: Parents hope that the son or daughter become self-reliant and independent; Selfcontrol: Parents hope that the son or daughter develop the ability to control negative impulses as aggression; Emotionality: Parents concern that the son or daughter develop the capacity for emotional relationships with others; Social expectations: Parents expect that son or daughter to perform according to the social expectations, such as being hardworking and honest; Good Behavior: Parents concern that the son or daughter plays well expected roles, as having a good relationship with others. The first two categories are associated with independent model, while the others belong to the interdependent model.

The question "What do you think he or she needs to develop these characteristics?" was analyzed in terms of possible strategy of action, adapted from categories used by Bandeira, Seidl-de-Moura and Vieira (2009). They are three: Self-centered: when parents serve as role models, as through the examples they set with their attitude; Context-centered: when mothers and fathers provide good social opportunities, as quality education; Person-centered: when the son or daughter participate actively in the development process, for example, having autonomy to decide what to do and where to go.

\section{RESULTS}

The results of this study will be presented considering socialization goals, parental strategies of action and the possible associations that mothers and fathers of people with spina bifida mentioned.

\section{Socialization Goals}

The question "How do you imagine your son's or daughter's life in the future?" resulted into five categories of socialization goals $(\mathrm{N}=52)$. First, it was found that families' most valued goal is selfimprovement $(51,92 \%)$, as it can be seen in the following reports: "(I hope) she has autonomy and takes 


\section{FAMILY OF PEOPLE WITH SPINA BIFIDA}

her own decisions ..." (P5); "(I hope) she lives her life positively, being confident, knowing how to handle mistakes, recognize and modify them (P7)".

The following category that those family members more valued was social expectations (25\%). This can be seen in the following reports: "(I hope he is) confident... social, curious" (P9); "(I hope she has) humor, tolerance, perseverance and empathy" (P11). On the other hand, the self-control category obtained low prevalence (7.69\%). It seems that the investigated families are little concerned about control negative impulses, such as aggression in their children and teenagers with disabilities. There was also little appreciation of emotionality category (related to emotional intimacy) and good behavior (related to the expectation that person can play their roles well in the future), with $7.69 \%$ each.

\section{Strategies of Action}

The question "What do you think he or she needs to develop these characteristics?" resulted into three categories of strategies of action $(\mathrm{N}=38)$ : self-centered, person-centered and context-centered. There was the prevalence of self-centered strategy $(55.26 \%)$. In turn, the person-centered strategy, which is related to children or teenagers with spina bifida, was the second more valued (26.32\%). Finally, the contextcentered strategy was less significant (18.42\%).

As the favorite one, self-centered strategy was also confirmed when the general vocabulary that participants used in this study are visualized. Figure 1 is a word cloud that shows the words that appear more frequently in the source text. As noted, "example" is the most used word which indicates that parents want their attitudes and character serve as references for the sons and daughters.

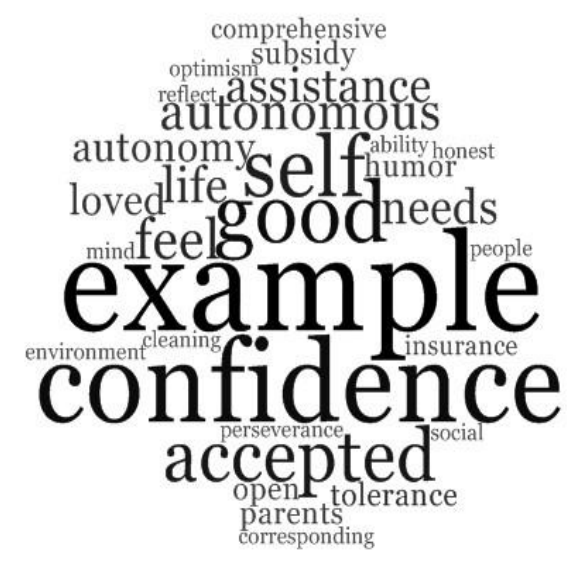

Figure 1.

Word cloud of the most frequent words used by participants.

Despite the importance of identifying the actions centered on a single agent (parent, person with spina bifida and context), it was noted that the participants also established links between strategies and goals. Then, data analysis continued, trying to understand what main strategies, grouped or not, mothers and fathers believed to contribute to the development of their children or teenagers. 


\section{Possible Association between Goals and Strategies}

Seeking a better understanding of how German mothers and fathers of people with spina bifida articulate their socialization goals with their practices, we proceeded with the search and identification of strategies that contribute to the achievement of certain goals. Figure 2 is a conceptual map that shows the possible relation between what parents expect for the son's or daughter's future and the strategy adopted in order to achieve the goals.

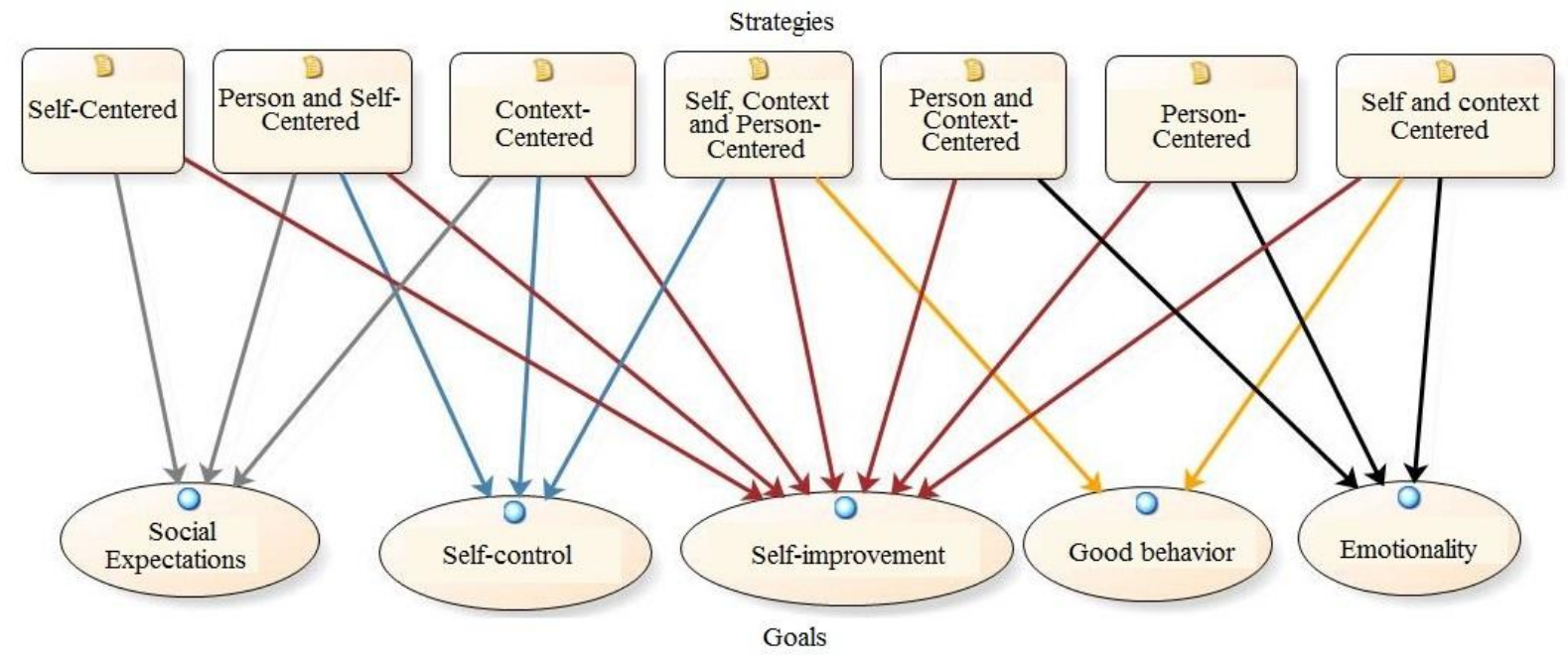

Figure 2.

Possible association between the strategies and the goals.

As a leading association, all the strategies adopted by parents of people with spina bifida are related to self-improvement goals. Besides, mothers and fathers believe that the strategies adopted by a single agent can enhance the achievement of other autonomy or relational goals. Thus, self-centered actions can contribute to the social expectations, for example: "I hope people have no prejudice against him" (P12). In turn, context-centered strategies can promote both social expectations and self-control: "I expect he has a fulfilling life and he can be confident" (P15). Otherwise, person-centered actions can contribute to the emotionality: "I expect she has joy in life" (P1).

On the other hand, the combined strategies among different agents showed that the person and selfcentered category can promote social expectations goals: "(I hope she is) honest, autonomous and punctual. I also hope she has good personal hygiene habits" (P17). The person and context-centered strategies contribute to emotionality, goal also contemplated in the self and context-centered category: "I hope she will have humor, tolerance, perseverance, empathy ... There must be a secure link between parents and children, with enough social contacts" (P11). In addition, the self, person and contextcentered strategy contribute to self-control and good behavior: "I hope she will become sensitive, selfconfident, autonomous, comprehensive, strong and have ability to negotiate conflicts... I can provide understanding, motivation, subsidies, assistance, such as educators, own experiences, good support" (P3).

\section{DISCUSSION}

First of all, it was observed that families' most valued goal is self-improvement. This idea that the son or daughter with spina bifida become self-reliant and independent is in line with the goals of other German families whose children and teenagers have a typical development (Keller et al., 2005). 


\section{FAMILY OF PEOPLE WITH SPINA BIFIDA}

According to these data, it seems that disability condition does not interfere in the goal that German families share culturally, which is the hope that their sons or daughters have autonomy, a characteristic associated with the independent model (Keller, 2007). Perhaps, since parents of people with spina bifida live in a developed country with guaranteed access to qualified services, including educational and health, it is possible for them to establish similar goals to other German families where there is typical development. This similarity of goals was also found in families of deaf children investigated by Freitas and Magalhães (2013). However, these findings differ from the parents investigated by Carvalho and Gondim (2012) who said to be uncertain about the future of sons and daughters with cerebral palsy.

The following important result showed that family members valued more social expectations. Note that although parents primarily have an interest that the son or daughter with spina bifida develop goals of autonomy, there is also an attention to the relationships and insertion in social groups. This specific interest is congruent with the data found by Barf et al. (2007) that showed German young people with spina bifida had high level of life satisfaction, including contact with friends and family members.

In terms of relationships, parents also expected that the son or daughter would recognize his or her disability condition does not represent he or she is superior or inferior to others. This can be identified in speech: "I take care of my daughter in a normal way and teach her to accept the disability, but I try to make her understand that this (condition) is not serious, it does not determine if she is a better or worse person" (P14). This parental desire was also identified in the parents' socialization goals investigated by Portes (2013), involving children with Down syndrome.

The following data was about self-control category which obtained low prevalence. This may be due to parenting practices are dependent on the child's health condition (Ievers, 1998), complemented by Prado (2005) who found that mothers of disabled people tend to be overprotective and have difficulty to make their son or daughter become independent.

There was also little appreciation of emotionality and good behavior categories. These results are in line with German families of sons and daughters with typical development (Keller et al, 2005 Durgel, Leyendecker, Yagmurlu \& Harwood, 2009), where some parents appreciated relational goals. On the other hand, this finding differs partially from those deaf children families investigated by Freitas and Magalhães (2013) where good behavior category was valued.

Considering the exposed data, it appears that the investigated families share the orientation of German families of people with typical development, which is value socialization goals related to independent model. However, although participants tend to follow the orientation of their cultural environment, they also valued relational goals, such as social expectation category, to their child or teenager with spina bifida.

Another result showed the prevalence of self-centered strategy of action. This suggests that in families of children and teenagers with spina bifida, parents feel that their participation is essential for their sons and daughters to develop their attributes, as shown in the statements: "I must always be there for my child when she needs me. I can assist her whenever she meets difficulties"(P17); "I want to take care of him and be there for him, but also show my own limits" (P11).

In other words, mother and fathers prefer to adopt strategies of action centered on parental resources to achieve the goals they have established. Thus, parents would be a reference or a model for the sons and daughters with spina bifida: "We can live as an example ... how we imagine ... and always praising successes" (P8). "I let my daughter see how Mom and Dad do chores ... living as an example" (P10). "I have to live as an example for him" (P12). This self-centered strategy of action was also found in the study involving other disabilities, such as deafness (Magalhães \& Freitas, 2013) and Down syndrome (Portes, 2013).

The second strategy parents valued was the person-centered one. A possible reason for this result is that spina bifida imposes a condition that limits the ability of a person to be autonomous and participate 
actively in their development process. Therefore, parental strategies of action have possibly been interfered by the disability condition, such as delay in the acquisition of skills related to autonomy highlighted by Holmbeck and Devine (2010).

When the goals and strategies of action were associated, it was observed that all parents' strategies are connected to self-improvement goals. This finding seems to show the necessity of participation of different actors (parent, person with spina bifida and environment) to promote practices that allow children and teenagers to develop skills related to autonomy, such as confidence and decision-making skills. Culturally shared, such appreciation for independence has been a parental strategy to the demands of the globalized world, as reported by Biasoli-Alves (1997).

Considering the findings in this study, it is possible to identify different aspects of the goals and strategies of action. On the one hand, German parents of people with spina bifida culturally share the socialization goals of autonomy, in other words, participants have similar beliefs to those found in other German families whose sons and daughters have typical development (Keller, 2007). On the other side, it was found that the parents in this study seem to believe that the achievement of goals for their children or teenagers can be enhanced through a combination of strategies of action. Perhaps, for these mothers and fathers, focus actions in a single agent would not be sufficient for achieving the goals established. Thus, they prefer to join forces with the context and child with disabilities seeking greater developmental gains.

In practical terms, this association of strategies reveals that participants need to have social support, including family and community. This aspect was also reported by Minetto, Crepaldi, Bigras and Moreira (2012), when argue that social support networks are essential to families of children with atypical development, especially to help them to reflect about their educational practices. In addition, social support can assist in difficulties resulting from neurological injury, as elucidated by Gaíva, Correa and Santos (2011) and limited social participation referred by Barf et al. (2007).

Thus, the combination of strategies and the need for support do not seem to be related to culture or environmental condition where families live in. In fact, disability condition of a son or daughter seems to be the major factor in the adoption of practices associated among the parents, the disabled person and the context, in order not only to promote the development, but also to obtain support in the parental role.

The socialization goals are part of parental beliefs that guide the strategies to be developed in the care of the new generations and these aspects help to understand how parents try to establish a commitment to their personal and social values (Leyendecker, Lamb, Harwood, \& Schölmerich, 2002). In line with that, we investigated the socialization goals and strategies that mothers and fathers have established for their son or daughter with spina bifida.

It was found that the most valuable goals are similar to other German families, suggesting that the disability condition does not interfere in the culturally shared beliefs. In order to achieve these goals, parents use, primarily, the self-centered strategy, which represents they serve as a model to their son or daughter with spina bifida. In addition, it was possible to identify that those mothers and fathers also need to combine different strategies in order to maximize the developmental gains.

This combination of strategies revels this group needs social support, which can be offered through actions that recognize not only the needs of disabled people, but also of family members (Guralnick, 2005). For example, family-centered interventions are supposed to identify needs and find resources to family groups, so that they use their skills and learn new ones related to caring their sons and daughters (Alves, 2009).

In the current study, results obtained are limited to the sample studied. Another limitation is related to the small number of participants, although the questionnaire had been available virtually in sites directed to people with spina bifida. For future research, it is suggested to consider goals and strategies of families 


\section{FAMILY OF PEOPLE WITH SPINA BIFIDA}

of people with spina bifida who live in other areas and cultures. Thus, there will be a progress in the understanding of the beliefs and parental practices related to disabled persons, in particular children and teenagers with spina bifida.

\section{REFERENCES}

Aguiar, M. J., Campos, Â. S., Aguiar, R. A., Lana, A. M. A., Magalhães, R. L., \& Babeto, L. T. (2003). Neural tube defects and associated factors among liveborn and stillborn infants. Journal of Pediatrics, 79, 129-134. doi: 10.1590/S0021-75572003000200007

Alves, M. M. (2009). Early Intervention and Special Education: Family-Centered Intervention Practices. Viseu: PsicoSoma.

Assis, C. P. D., \& Martinez, C. M. S. (2011). The school inclusion of students with myelomeningocele. Journal of Occupational Therapy UFSCar, 19, 307-322. doi: 10.4322/

cto. 2011.004

Bandeira, T. T. A., \& Seidl-de-Moura, M. L. (2012). Mothers and fathers' beliefs about parental investment. Paidéia, 22, 355-363. doi: 10.1590/S0103-863X2012000300007

Bandeira, T. T., Moura, M. L. S. D., \& Vieira, M. L. (2009). Mothers' and fathers' socialization goals for their children. Brazilian Journal of Human Growth and Development, 19, 445-456.

Bardin, L. (1979). Content Analysis. Lisbon: Editions.

Barf, H. A., Post, M. W. M., Verhoef, M., Jennekens-Schinkel, A., Gooskens, R. H. J. M., \& Prevo, A. J. H. (2007). Life satisfaction of young adults with spina bifida. Developmental Medicine \& Child Neurology, 49, 458-463. doi: 10.1111/j.1469-8749.2007.00458.x

Bartonek, ̊. (2010). Motor development toward ambulation in preschool children with myelomeningocele - a prospective study. Pediatric Physical Therapy, 22, 52-60. doi: 10.1097/PEP.0b013e3181cc132b

Biasoli-Alves, Z. M. M. (1997). Brazilian families of the twentieth century: values and child-rearing practices. Psychology themes, 3, 36-49.

Couto, T.H.A.M., Tachibana, M., Vaisberg, T.M.J.A. (2007). Mother, child and Down syndrome. Paidéia, 17, 265-72. doi: 10.1590/S0103-863X2007000200010

Durgel, E. S., Leyendecker, B., Yagmurlu, B., \& Harwood, R. (2009). Sociocultural influences on German and Turkish immigrant mothers' long-term socialization goals. Journal of Cross-Cultural Psychology, 40, 834-852. doi: 10.1177/0022022109339210

Freitas, H. R. M. D., \& Magalhães, C. M. C. (2013). Socialization Goals and Strategies for Deaf Children That Their Mothers Value for Their Children. Brazilian Journal of Special Education, 19, 545561.

Gaíva, M. A. M., Corrêa, E. R., \& Santo, E. A. R. E (2011). Clinical and epidemiological profile of children and adolescents who live with spina bifida. Journal of Human Growth and Development, 21, 99110. doi: 10.1590/S0104-12822011000100010

Gaiva, M. A. M., Neves, Á. D. Q., \& Siqueira, F. M. G. D. (2009). The care of children with spina bifida in the family home. Anna Nery School, 13, 717-725. doi: 10.1590/S1414-81452009000400005

Gondim, K. M., Carvalho, Z. M. F. (2012). The mothers of children with cerebral palsy feelings motivated by the mishel's theory. Anna Nery School, 16, 11-16.

Guralnick, M. J. (2005). Early Intervention for Children with Intellectual Disabilities: Current Knowledge and Future Prospects*. Journal of Applied Research in Intellectual Disabilities, 18, 313-324. doi: 10.1111/j.1468-3148.2005.00270.x 
Harkness, S., \& Super, C. (1996). Themes and variations: Parental ethnotheories in western cultures. In: K. Rubin, \& O. B. Chung (Eds.). Parental beliefs, parenting, and child development in cross-cultural perspective (pp. 61-79). New York: Psychology Press.

Holmbeck, G. N., \& Devine, K. A. (2010). Psychosocial and family functioning in spina bifida. Developmental disabilities research reviews, 16, 40-46. doi: 10.1002/ddrr.90

Ievers, C. E. (1998). Maternal child-rearing behavior in cystic fibrosis. Dissertation Abstracts International, 58(10-B), 5646.

Kagitcibasi, Ç. (2007). Family, self and human development across cultures: Theory and applications. Mahwah: Lawrence Erlbaum.

Keller, H., Lamm, B., Abels, M., Yovsi, R., Borke, J., Jensen, H., et al. (2006). Cultural models, socialization goals and parenting ethnotheories: A multicultural analysis. Journal of Crosscultural Psychology, 155-172. doi: 10.1177/0022022105284494

Keller, H. (2007).Cultures of infancy. Mahwah: Lawrence Erlbaum Associates.

Keller, H., Borke, J., Yovsi, R., Lohaus, A., \& Jensen, H. (2005). Cultural orientations and historical changes as predictors of parenting behaviour. International Journal of Behavioral Development, 29, 229237. doi: $10.1177 / 01650250544000017$

Kobarg, A. P., Sachetti, V. A., \& Vieira, M. L. (2006). Values and believes parental: theoretical considerations. Brazilian Journal of Human Growth and Development, 16, 96-102.

Leyendecker, B., Lamb, M. E., Harwood, R. L., \& Schölmerich, A. (2002). Mothers' socialization goals and evaluations of desirable and undesirable everyday situations in two diverse cultural groups. International Journal of Behavioral Development, 26, 248-258. doi: 10.1080/01650250143000030

Miller, A. M, \& Harwood, R. L. (2001). Long-term socialization goals and the construction of infants' social networks among middle class Anglo and Puerto Rican mothers. International Journal of Behavioral Development, 25, 450-7. doi: 10.1080/016502501316934888

Minetto, M.F, Crepaldi, M. A., Bigras, M., \& Moreira, L. C. (2012). Educational practices and parental stress in parents of young children with typical and atypical development. Educating in Journal, 117-132.

Moinhos, M. V. C., Lordelo, E. R., \& Seidl-de-Moura, M. L. (2007). Socialization goal of mothers from Bahia in different socioeconomic contexts. Brazilian Journal of Human Growth and Development, 17, 114-125.

Nuernberg, A. H. (2008). Vygotski's contributions for the education of visually disabled people. Study in Psychology, 13, 307-316.

Portes, J. R. M. (2013). Beliefs about care practices and socialization goals of parents with children with Down syndrome. Doctoral dissertation, Federal University of Santa Catarina.

Prado, A. F. A. (2005). Family and disability. In C. M. O Cerveny (Org.). Family and ...: communication, divorce, change, resilience, disability, law, bioethics, disease, religion and drug addiction. São Paulo: House of the Psychologist.

Sari, F. L., \& Marcon, S. S. (2008). Participation of the family in physical therapy treatment of children with cerebral palsy. Brazilian Journal of Human Growth and Development, 18, 229-239.

Sousa, J.I.G.S., Ribeiro, G.T.F., Melo, A.P.C. (2009). Down's syndrome: feelings lived by the parents upon the diagnosis. Pediatrics, 31, 100-8.

Teixeira, M. A. P., Oliveira, A. M., \& Wottrich, S. H. (2006). Parental Practices Scales (PPS): evaluating dimensions of parental practices towards adolescents. Psychology: Reflection and Criticism, 19, 433-441.

Wiart, L., Ray, L., Darrah, J., \& Magill-Evans, J. (2010). Parents' perspectives on occupational therapy and physical therapy goals for children with cerebral palsy. Disability \& Rehabilitation, 32, 248-258. doi: $10.3109 / 09638280903095890$ 